\title{
Cloud-Based Mobile Learning
}

\author{
Alexandru BUTOI, Nicolae TOMAI, Loredana MOCEAN \\ Babeş-Bolyai University, Business Information Systems Department \\ alex.butoi@econ.ubbcluj.ro,nicolae.tomai@econ.ubbcluj.ro, \\ loredana.mocean@econ.ubbcluj.ro
}

As the cloud technologies are largely studied and mobile technologies are evolving, new directions for development of mobile learning tools deployed on cloud are proposed.. MLearning is treated as part of the ubiquitous learning paradigm and is a pervasive extension of E-Learning technologies. Development of such learning tools requires specific development strategies for an effective abstracting of pedagogical principles at the software design and implementation level. Current paper explores an interdisciplinary approach for designing and development of cloud based M-Learning tools by mapping a specific development strategy used for educational programs to software prototyping strategy. In order for such instruments to be user effective from the learning outcome point of view, the evaluation process must be rigorous as we propose a metric model for expressing the trainee's overall learning experience with evaluated levels of interactivity, content presentation and graphical user interface usability.

Keywords: M-learning, Quality Metrics, Cloud Computing, Software design, Mobile Learning

1 Introduction

As cloud systems development is moving further, more and more web-based and mobile applications are developed using cloud technologies. These technologies provide elasticity and flexibility of the resources for cloud-enabled applications. Cloud computing provides datacenter computing power and storage. E-Learning and M-Learning tools can benefit from cloud technology expansion and can be easily developed as cloud-enabled applications. Cloud-enabled M-learning applications have the advantage of resource elasticity and will eliminate the device resource limitations.

National Institute of Standards and Technology (NIST) [1] defines cloud computing as a computing model which offers network access to a configurable resource pool, the access being location transparent, convenient and on-demand. These resource pools consist of networks, servers, storage, applications and services which can be used by the end user with a minimum management effort and interaction with the cloud provider. Same report [1] identifies three models for services delivery in cloud computing: Software as a Service (SaaS), Platform as a Service (PaaS) and Infrastructure as a Service (IaaS). As [2] extends the list of service model delivery in cloud computing, a Learning as a Service (LaaS) model could be considered for cloudenabled learning tools including cloud Elearning systems and cloud M-learning systems.

According to [3] M-Learning is part of ubiquitous learning paradigm and has two dimensions: (a) physical space and timetables independency (pervasive) and (b) immediate access to resources due to its distributed nature. Consequently, M-Learning can be a powerful instrument for continuous learning process, as mobile technologies and infrastructures expands.

This paper studies de feasibility and applicability of mobile cloud-based learning solutions, identifies the main requirements and proposes a development strategy of such systems. Accordingly, we designed an MLearning platform prototype and we conducted an experiment within the students of Business Information Systems department in order to evaluate the end-user experience, utility and satisfaction, identifying the main requirements and challenges based on the users' feedback, work presented in [4]. Furthermore we conducted a statistical analysis regarding the four different evaluated issues: 
Overall M-Learning experience in relation with Content presentation, Graphical User Interface interaction and Interactivity, defining a metric to quantify the effectiveness of the prototype from the end-users' point of view.

This paper represents an extended version of [4] and it is structured as follows: section 2 presents some relevant approaches from the existing literature, section 3 details the specific methodology used for development and evaluation of the prototype while section 4 presents the data analysis that was conducted, followed by section 5 where the overall experience metric is built, ending with conclusions and future development.

\section{Related Work}

Social and technological context determined a reconsideration of the solutions regarding learning process and tools. The technological changes in the mobile and wireless industry have brought new and modern learning methods based on real-world scenarios. Students are now using mobile devices in their learning process as a better alternative to traditional studying which implies a limited access to information without being limited by time and space constraints. A more approachable learning alternative involves using technology and well-designed learning methods which ensure a significant change in the students' learning achievements [5]. Hwang and Chang [5] present a detailed study about m-learning strategies by applying a formative assessment-based learning guiding mechanism as a modern learning alternative. The study involved two learning groups who had the same amount of time to complete the learning tasks. The first group used the assessment-based learning approach and is referred as the FAML (Formative Assessment-based Mobile Learning) group while the second group was conducting a conventional m-learning method. Even though both groups used mobile devices in their learning process, the study showed a major difference in the way students interacted with the learning system. The FAML technique encouraged answer discovery by offering hints and seemed to be a better learning strategy as it provided a more challenging and motivating learning environment. The study helps in developing new learning scenarios that combine both real-world and digital-world resources. Experiments have proven that personalization of the e-learning process increases the users' learning outcome. Modern learning systems are increasingly designed as serious games [6] or educational games which are a powerful instrument for learning complex issues. Moreover, [7] examines the foundations of these games and proposes a design methodology for them, while [8] demonstrates that educational games create an increased level of motivation in a competitive and collaborative environment setup like learning networks. Chu et. al. [9] present a mobile learning system that uses Radio Frequency Identification (RFID) technology which helps in examining real-world learning behaviours in specific situations. This innovative method shows that elementary school students were highly receptive to this mobile learning system and their learning motivation has increased by using the system. The developed system known as the $\mathrm{T} 3 \mathrm{G}$ supports u-learning activities and was highly appreciated by the students who showed a willingness to share their experience with other classmates. A questionnaire survey was conducted in order to discover new learning scenarios using the T3G approach.

Hulme et. al.[10] consider that the European perspective is not only interested in the general connection between formal and informal learning but it is also characterized by pedagogical aspects that can improve the learners participation and can help in developing theoretical perspectives on mobile learning. Among the mobile learning projects developed in Europe, the authors present a series of relevant projects conducted between 2003 and 2008 in three different environments: MLearning in School Settings, M-Learning in University Settings, M-Learning in Museums and Informal Learning Settings and MLearning for Professional Development and Workplace Settings. In the mobile learning in schools sector, the most important projects 
were Learning2Go (2006) and ENLACE (2007) while in the university sector projects such as StudyLin (2007), Pls Turn UR Mobile On (2006) and myPad(2008) were highly debated. Mobile learning in museums and informal learning projects included Mystery at the museum (2005) and MyArtSpace (2007) while the last category presenting professional development and workplace projects included applications such as MeduMobile(2006) and Flex-Learn(2008) [10]. Goh[3] provides a comprehensive view of the M-Learning field in relation with ubiquitous learning paradigm among e-learning and virtual learning tools. It consists of a theoretical overview of the domain, design and integration methodologies, innovative tools and cases. Ubiquitous learning known as Ulearning is a learning activity in which participants become immersed in the learning activity and is developed by providing an interoperable architecture where students can share learning resources among the community [11]. M-Learning takes into consideration serious games and collaborative learning tools, [12] identifying some fundamental requirements for designing and implementation of distributed and self-adaptive mobile systems for fitting the trainee's needs. Motiwalla [13] proposes a development framework for pervasive and distance learning, extending elearning to mobile learning. The importance and adoption of mobile technologies have been studied using application prototypes and collecting the feedback from them. A similar approach is presented in [14] by studying the acceptance of M-Learning system using the feedback provided by the students while identifying several factors with positive influence on trainees.

In order to evaluate the u-learning effectiveness the authors of [11] conducted a survey on 32 fifth grade students in Taiwan and the evaluation results were presented in three sections: the Macro view, the Micro view and U-learning refinement. Evaluation criteria at the Macro level was represented by five dimensions: Active, Cooperative, Authentic, Constructive, Personalized. Results show that only "authentic" was satisfactory while "ac- tive", "constructive", and "personalized" were ordinary, and "cooperative" was unsatisfactory. At the Micro level aspects such as context awareness, personalization service, situation of instructional activity, initiative of knowledge acquisition, constructivist learning, urgency of learning need, adaptive learning, interactivity of learning process, selfregulated learning, and learning community were considered relevant. A set of inefficient criteria such as learning community, selfregulated learning, and interactivity of learning process was discovered.

When measuring performance, users need to include aspects defined in ISO/IEC 9126 such as functionality, reliability, usability, efficiency, maintainability, portability and quality in use as Ruti Gafni [15] developed a set of quality metrics which are currently extending the ISO/IEC 9126 quality standard for mobile-wireless information systems and are known as the "Display load" metric and "Memory cleanup" metric tested in two different experiments. The study concludes that these metrics are very useful when comparing two different systems and when a decision has to be taken regarding the best alternative.

\section{Methodology}

As stated previously in [4] the research process was conducted in four phases: development of m-learning system prototype, evaluation of the student's learning experience, collecting the feedback data using a survey and direct observation and analysis of collected data.

\subsection{M-Learning Prototyping}

Virtual learning field of knowledge is interdisciplinary being a mix of pedagogical knowledge and technical information systems knowledge. The design of such systems must model and implement the principles of pedagogical content delivery in form of software systems as tools for learning specific domains. Building M-Learning systems which has to enable high quality learning experience for the trainees requires a design strategy which must be adequate from the 
software engineering point of view as it must not contradict the design principles and knowledge of educational instruments and programs development. A convergence point between the two knowledge fields of soft-

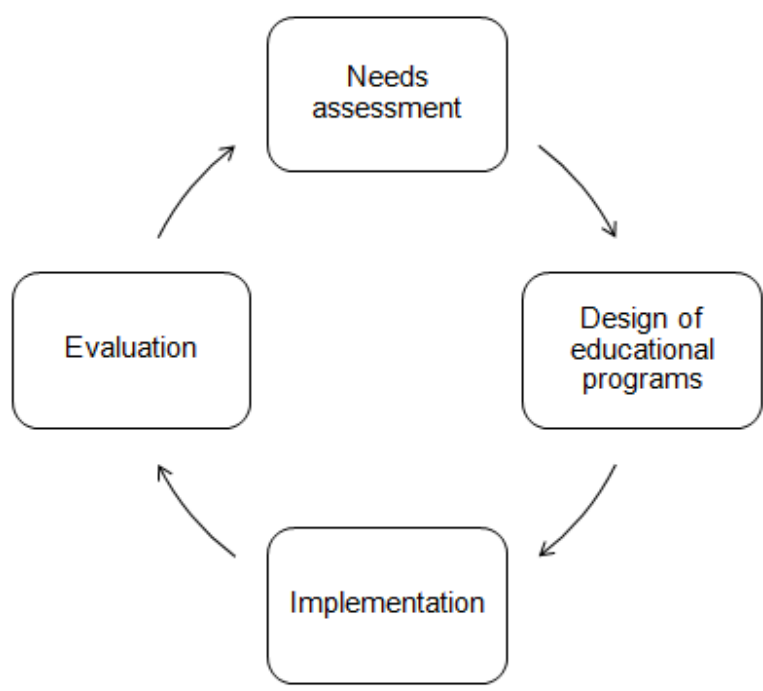

Fig. 1. Educational project life cycle [16]

The development process of the educational projects depicted in Figure 1 is a four phases cycle which is very similar to software prototyping phases depicted in Figure 2 [17]:

(1) educational needs assessment phase refers to identifying the capabilities and knowledge that should be thought; the phase outcome represents the pedagogical foundation and guidelines for the software prototype general requirements and objectives;

E.g. pedagogical need: easy to understand content / software requirement: user friendly, easy to read content delivery.

(2) design of educational program asses the teaching process - how to deliver the educational content and it provides the functional requirements and usage workflow of the prototype;

E.g. pedagogical design: interactive workshop and assignments / prototype design: interactive content delivery and interactive serious games for skill development

(3) implementation of educational program represents the methodology for deliver- ware engineering and educational projects design must be found. Accordingly, [16] proposes an iterative design process of such educational programs, as Figure 1 depicts.

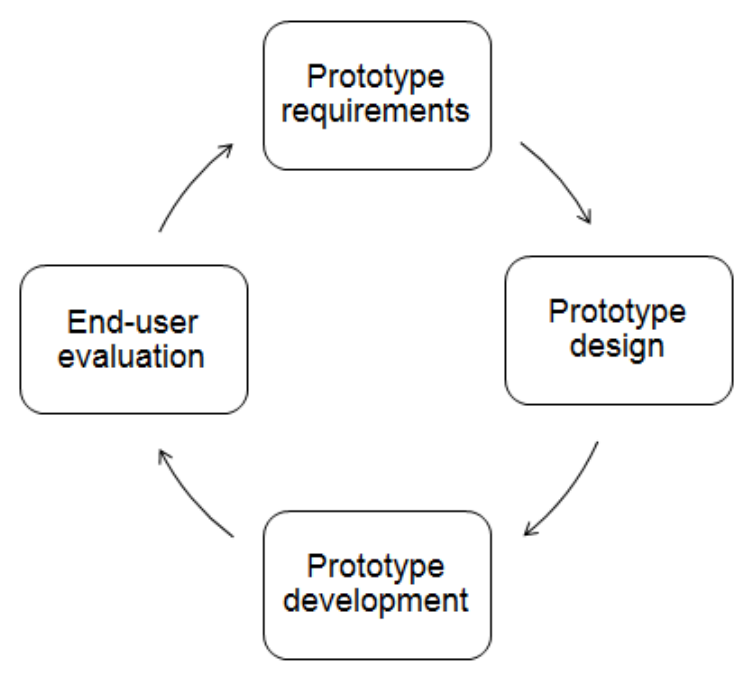

Fig. 2. Software prototyping [17]

ing the designed educational program and provides the detailed software prototype model for delivering educational content;

E.g. pedagogical implementation: trainees attend to presentations and then they are provided with practical educational activities / software implementation: user selects a lesson for study and then they have to complete a puzzle game practice for the previous lesson;

(4) evaluation phase refers to feedback assessment and continuous improvement of the education process, similar to prototyping, where users feedback and raised issues are gathered in order to further improve and develop the prototype - the evaluation outcome may provide further requirements for the future prototype.

Our prototype was implemented using Microsoft's ASP.NET MVC 4 framework for Mobile Development and was deployed on a virtualized infrastructure using IIS 7 web server and Windows Server operating system. As database server for data storage we use Microsoft SQL Server 2008 Express. 
From the hardware point of view, the virtualized server was initially allocated with 2 GB RAM memory, 2 CPUs and $30 \mathrm{~GB}$ of data storage. The advantage of cloud based deployment is mainly the elasticity of the resources: if a hardware resource becomes insufficient we can simply add extra virtualized resources to the existing ones without any extra effort.

For interactivity and compatibility with mobile devices we used HTML 5 and jQuery libraries and plug-ins. The user interface is lightweight and very adaptable to mobile display dimensions. The M-learning prototype is compatible with many types of devices such as smart-phones and tablets and even desktop computers or laptops via an Internet browser. The application has 2 sections: Topics sections - presents short $\mathrm{C}$ programming lessons and Practice games serious educational games. Topics sections consists of short standardized and comprehensive lessons specially designed for mobile display. Every lesson is structured as follows: title, syntax specification, role and scope of concept, usage and applicability of concept and a short example. Every page is provided with navigation buttons for returning to lesson summary or for attending new lessons and practice activities. The Practice section provides programming assignments where trainees have to solve puzzles of source code lines in order to obtain the correct $\mathrm{C}$ programs. Using navigation panes included at the bottom of the sections trainees are guided trough a continuous and coherent learning process alternating topic presentations with practice activities.

\subsection{Prototype Evaluation}

The first evaluation of the prototype was conducted among 57 second year students from business information systems, enrolled to computer programming course. The experiment was assisted by a member of the research team and was ran as follows: first the subjects were told to access the platform from their mobile devices, study the content topics and play practice games in order to get familiar with the learning environment for 15 minutes. While they were using the $\mathrm{M}$ Learning platform their actions and navigation times where recorded in the system as $\operatorname{logs}$ for further analysis. After they interacted with the M-Learning environment the students were asked to fill a survey in order to evaluate the applicability, utility and user experience of the M-Learning process. During the learning process direct observations were gathered too. Evaluation process aimed to determine the users' feedback regarding the system, users' expectancies related to the educational content, requirements of the future prototypes, infrastructure requirements and possible improvements of the prototype. The survey was formed from 20 questions which evaluated 4 main aspects:

1. infrastructure requirements and availability depicted in Table 1;

2. users' expectancies regarding the informational content to be provided - Table 2 ;

3. users' expectancies and beliefs in terms of utility and usability - Table 3 ;

4. user experience in terms of interactivity accessibility and usability of the application depicted and analysed on next sections (4 questions using scales);

Table 1. Infrastructure related survey items

\begin{tabular}{|l|l|l|}
\hline ID & \multicolumn{1}{|c|}{ Item } & \multicolumn{1}{|c|}{ Relevant Responses (\%) } \\
\hline 1 & $\begin{array}{l}\text { How often do you carry a mobile device? } \\
\text { Almost Never / Often / Sometimes / Almost Always /Always }\end{array}$ & $\begin{array}{l}\text { Almost Always - 23\% } \\
\text { Always - 77\% }\end{array}$ \\
\hline 2 & $\begin{array}{l}\text { When you do not carry a mobile device with you? } \\
\text { Morning / Afternoon / Night/ Only when I forgot it / Never }\end{array}$ & $\begin{array}{l}\text { Morning }-2 \% \\
\text { Night }-19 \% \\
\text { Never }-27 \% \\
\text { Forgot }-52 \%\end{array}$ \\
\hline 3 & $\begin{array}{l}\text { Where do you use the mobile phone most frequently? } \\
\text { Home/ School or Work/ Travelling/ Other places }\end{array}$ & $\begin{array}{l}\text { Home }-37 \% \\
\text { School or Work }-44 \% \\
\text { Travelling - 14\% }\end{array}$ \\
& & Other places -5\% \\
\hline 4 & Do you have a WiFi connection on your mobile phone? & YES - 77\% \\
\hline
\end{tabular}




\begin{tabular}{|c|c|c|}
\hline ID & Item & Relevant Responses (\%) \\
\hline & YES / NO & $\mathrm{NO}-23 \%$ \\
\hline 5 & $\begin{array}{l}\text { Do you have an Internet mobile data connection like } 3 \mathrm{G}, 4 \mathrm{G} \text { or other } \\
\text { types? YES/ NO }\end{array}$ & $\begin{array}{l}\text { YES }-63 \% \\
\text { NO }-37 \%\end{array}$ \\
\hline 6 & $\begin{array}{l}\text { Which is the most frequent mobile phone activity of yours? } \\
\text { SMS-MMS/ Calls/ E-mail/ Entertainment/ Internet/ Others }\end{array}$ & $\begin{array}{l}\text { SMS-MMS - 14\% } \\
\text { Calls - } 67 \% \\
\text { Entertainment - } 4 \% \\
\text { Internet - } 14 \% \\
\text { Others - } 1 \%\end{array}$ \\
\hline
\end{tabular}

•

Table 2. Content preferences related survey items

\begin{tabular}{|l|l|l|}
\hline ID & \multicolumn{1}{|c|}{ Item } & \multicolumn{1}{|c|}{ Relevant Responses (\%) } \\
\hline 7 & $\begin{array}{l}\text { Would you like to have access to your grades using your mobile phone? } \\
\text { Dislike / Neutral / I would like it / Great idea }\end{array}$ & $\begin{array}{l}\text { Neutral - 3\% } \\
\text { I would like it - 37\% } \\
\text { Great idea - 60\% }\end{array}$ \\
\hline 8 & $\begin{array}{l}\text { What would you like the most to access trough M-learning system? } \\
\text { Courses/ Seminars/ Both }\end{array}$ & $\begin{array}{l}\text { Courses - } 11 \% \\
\text { Seminars - } 1 \% \\
\text { Both - 88\% }\end{array}$ \\
\hline
\end{tabular}

Table 3. Users' beliefs and expectancies related survey items

\begin{tabular}{|c|c|c|}
\hline ID & Item & Relevant Responses (\%) \\
\hline 9 & $\begin{array}{l}\text { What do you think about installing mobile applications? } \\
\text { Very unsecure/ Little unsecure / Neutral / I trust some vendors / I don't } \\
\text { have any problem with that }\end{array}$ & $\begin{array}{l}\text { Very unsecure }-4 \% \\
\text { Little unsecure }-23 \% \\
\text { Neutral }-23 \% \\
\text { Trusted vendors }-18 \% \\
\text { No problem }-32 \%\end{array}$ \\
\hline 10 & $\begin{array}{l}\text { What do you think of a feature for stay in touch with your professors using } \\
\text { mobile phones? } \\
\text { Very Uncomfortable / Little Uncomfortable / Neutral / Comfortable / I } \\
\text { would like that feature }\end{array}$ & $\begin{array}{l}\text { Very Uncomfortable }-2 \% \\
\text { Little Uncomfortable-23\% } \\
\text { Neutral }-16 \% \\
\text { Comfortable }-40 \% \\
\text { I would like } . . .-19 \%\end{array}$ \\
\hline 11 & $\begin{array}{l}\text { Do you think that having mobile access to educational content would be in } \\
\text { your benefit? } \\
\text { Absolutely no/ No/ Neutral / Probably/ Absolutely Yes }\end{array}$ & $\begin{array}{l}\text { Absolutely no }-2 \% \\
\text { No }-2 \% \\
\text { Neutral }-5 \% \\
\text { Probably }-28 \% \\
\text { Absolutely yes }-63 \%\end{array}$ \\
\hline 12 & $\begin{array}{l}\text { Would you install mobile applications to gain mobile access to educational } \\
\text { resources? Probably NO / YES }\end{array}$ & $\begin{array}{l}\text { Probably NO }-2 \% \\
\text { YES }-98 \%\end{array}$ \\
\hline 13 & $\begin{array}{l}\text { Would you buy a new mobile device with higher performances in order to } \\
\text { have mobile access to educational resources? } \\
\text { NO / Probably NO/ I do not know/ Probably/ YES }\end{array}$ & $\begin{array}{l}\text { NO }-9 \% \\
\text { Probably NO }-11 \% \\
\text { I do not know - 9\% } \\
\text { Probably - 44\% } \\
\text { YES - 28\% }\end{array}$ \\
\hline 14 & $\begin{array}{l}\text { Do you think that usage of a Mobile Learning solution could improve your } \\
\text { educational activities? } \\
\text { NO / Probably NO / I am not sure / Probably YES/ YES }\end{array}$ & $\begin{array}{l}\text { NO }-4 \% \text { YES }-12 \% \\
\text { Probably NO }-5 \% \\
\text { I am not sure }-25 \% \\
\text { Probably YES }-54 \%\end{array}$ \\
\hline 15 & $\begin{array}{l}\text { In which context would you use such M-Learning application? At home - } \\
\text { spare time / At work or school / When I am waiting in queue / Other }\end{array}$ & $\begin{array}{l}\text { At home, spare time }-35 \% \\
\text { At work or school }-37 \% \\
\text { In queue }-22 \% \\
\text { Other }-6 \%\end{array}$ \\
\hline
\end{tabular}

The overall experience, interactivity, content presentation and user interface was evaluated using 1 to 10 scales. The remaining 2 question where used to include users into the sample and are not relevant for the study. The survey was applied to 57 students and data was analysed using IBM SPSS 16.0. Next we will concentrate on data analysis especially on the four data distributions which evaluates the M-learning experience, calculating the reliability and correlations between them in order to build a metric for expressing the overall M-Learning experience provided by the prototype.

\section{Data Analysis}

The data analysis of the collected data follows the four issues evaluated in the applied 
survey and the most significant findings are summarized in Table 4.

Table 4. Data Analysis Summary

\begin{tabular}{|l|l|}
\hline \multicolumn{2}{|c|}{ INFRASTRUCTURE } \\
\hline Availability & $77 \%$ always carry devices \\
\hline Usage & $44 \%$ usage at school and work \\
\hline WiFi Connectivity & $77 \%$ have WiFi connection \\
\hline Data Connectivity & $63 \%$ - have data connectivity (3G, 4G, etc.) \\
\hline \multicolumn{2}{|c|}{ USER EXPECTANCIES AND BELIEFS } \\
\hline Application Install & $50 \%$ feel unsecure or neutral \\
\hline Access to grades & $60 \%$ - excellent idea \\
\hline Future benefits & $63 \%$ - it would be a benefit \\
\hline Prospected utility & $84 \%$ - cannot quantify the utility \\
\hline
\end{tabular}

a. Infrastructure requirements and availability of mobile infrastructure for the evaluated sample is acceptable. More than $77 \%$ of the respondents always carry their devices and $44 \%$ of them use their phone at school or work. The connectivity represents a necessary requirement for a web-based system and it is at acceptable level as we found that $77 \%$ percent of the respondents can connect their mobile devices to Internet using WiFi technologies and $63 \%$ of the respondents have mobile data connection to Internet. [4]

b. Users' expectancies and beliefs evaluation suggests, as presented in [4], that webbased approach is the best approach for this type of system because it can be accessed not only from mobile devices, but from the desktops and laptops too.

Regarding the acceptance level of mobile software alternatives, users seems to be reserved when comes to installing applications on their mobile phones: $50 \%$ of users feel unsecure when installing applications on their devices or they cannot give an answer, while 50\% are more opened for installing mobile applications.

When asked if they would like to have access to their grades trough a mobile application,
$37 \%$ responded positively and $60 \%$ of the users considered it as an excellent idea. Furthermore, $63 \%$ of them agreed that having access to educational resources would definitely be a benefit. An interesting finding is that $80 \%$ of the students are uncertain about how M-Learning solutions will bring benefits to their educational activity, explained by the novelty of the field and lack of such systems. Regarding the informational content, $84 \%$ of the respondents would like to have both courses and laboratories available to their mobile devices.

c. User experience represents the corner stone of our study and it is evaluated using a 1 to 10 scale base in terms of overall experience appreciation, GUI usability, interactivity and content accessibility. Figures 1-4 presents the distribution of the four evaluated issues of our M-Learning prototype regarding Overall M-Learning experience (Figure 3), graphical interface (Figure 4), content presentation evaluation (Figure 5) and interactivity (Figure 6). All four issues were evaluated within the survey using 1 to 10 scales. The trainees were asked to appreciate the forth issues on a scale from 1 to 10,1 meaning very unattractive and 10 meaning very attractive. 


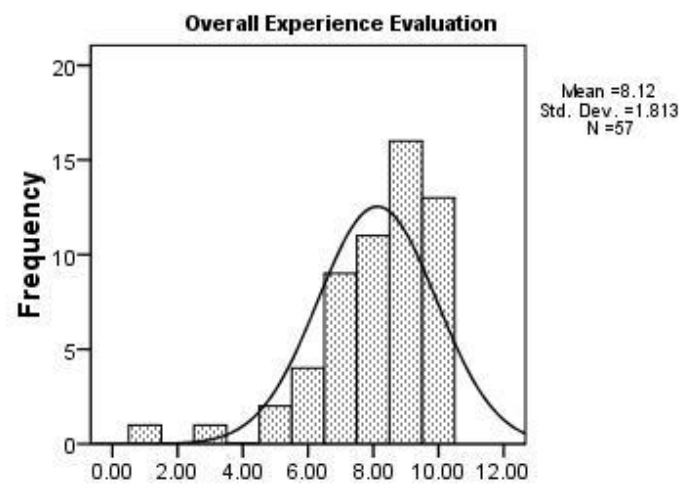

Fig. 3. Overall M-Learning Evaluation

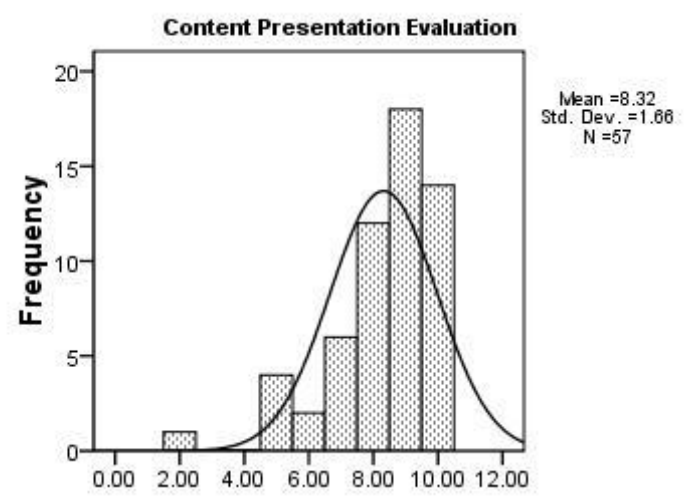

Fig. 5. Content Presentation Evaluation

Table 5 depicts the statistical evaluation approach of the four issues. We observe that for every evaluated issue we have an average between 8.1 and 8.3, leading to the conclusion of high quality M-Learning user experience. The Skewness is negative for all four variables meaning that all values tend to be concentrated to the higher values of the scale.

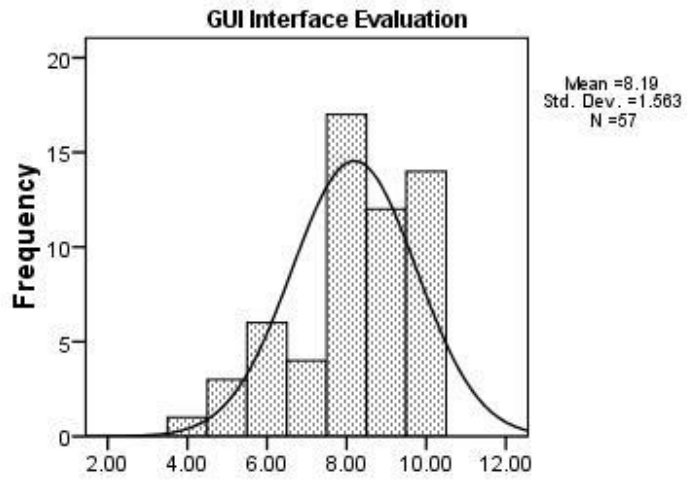

Fig. 4. Interface Accessibility Evaluation

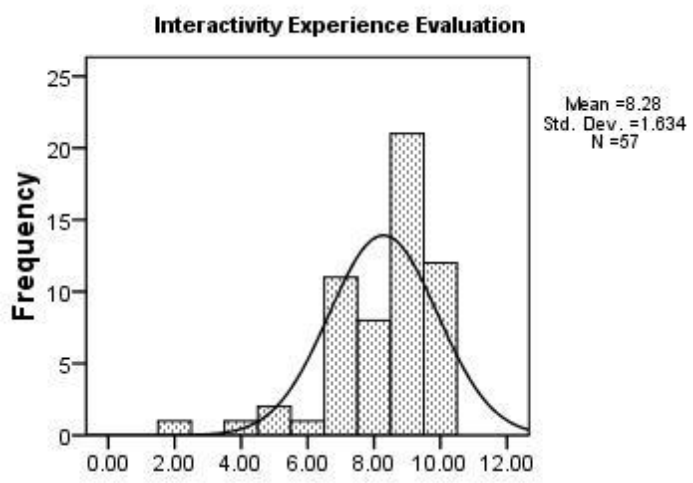

Fig. 6. Interactivity Evaluation

Because we deal with user experience evaluation which is a psychometric evaluation, we need to test the internal consistency (reliability) of the analyzed scale distributions. We ran the Cronbach-Alpha test and we obtained a Cronbach Alpha value of $\mathbf{0 . 9 0 8}$ which is greater than 0.9 , meaning that reliability level is excellent.

Table 5. M-Learning Experience Evaluation Statistics

\begin{tabular}{|l|r|r|r|r|}
\hline Indicator & Overall experience & GUI Interface & Content Presentation & \multicolumn{1}{c|}{ Interactivity } \\
\hline $\mathrm{N}$ & 57 & 57 & 57 & 57 \\
\hline Mean & $\mathbf{8 . 1 2 2 8}$ & $\mathbf{8 . 1 9 3 0}$ & $\mathbf{8 . 3 1 5 8}$ & $\mathbf{8 . 2 8 0 7}$ \\
\hline Median & 9.0000 & 8.0000 & 9.0000 & 9.0000 \\
\hline Std. Deviation & 1.81335 & 1.56341 & 1.66001 & 1.63395 \\
\hline Skewness & $\mathbf{- 1 . 5 8 6}$ & $\mathbf{- . 7 3 9}$ & $\mathbf{- 1 . 4 7 3}$ & $\mathbf{- 1 . 5 4 1}$ \\
\hline Kurtosis & 3.670 & -.099 & 2.766 & 3.220 \\
\hline Minimum & 1.00 & 4.00 & 2.00 & 2.00 \\
\hline Maximum & 10.00 & 10.00 & 10.00 & 10.00 \\
\hline
\end{tabular}

Next we explored the correlations between overall experience and other three distributions: content presentation, interactivity and GUI interaction. Previously we tested our distribution for normality, uniformity, and other particular distributions and we cannot assume that they follow a normal distribution and as consequence non-parametric correlation tests are suitable for our case. We computed the Spearman and Kendall tau-b correlations ranks, the results being depicted in Table 6 . We observe that we have significant 
correlation between Overall experience and the other distributions.

Table 6. Correlation between Overall Experience and the other distributions

\begin{tabular}{|l|l|r|r|r|}
\hline \multicolumn{1}{|c|}{ Correlation } & & \multicolumn{1}{c|}{ GUI Interface } & Content Presentation & \multicolumn{1}{c|}{ Interactivity } \\
\hline Kendall's tau_b & Overall experience & $.447^{* *}$ & $.592^{* *}$ & $.602^{* *}$ \\
\hline Spearman's rho & Overall experience & $.530^{* * *}$ & $.683^{* * *}$ & $.683^{* *}$ \\
\hline
\end{tabular}

These correlations can be further studied in order to build quality metrics for M-Learning experience. In the next section we will try to build a metric for expressing Overall experience as a metric function depending on GUI Interface, Content Presentation and Interactivity, building a metric model in a functional form $y=f(X)$ where $X$ is the factor matrix [18].

\section{M-Learning Experience Evaluation Metric}

In this section we propose a metric for expressing the overall M-learning experience using the other tree correlated factors: GUI Interface, Content Presentation and Interactivity. Building the evaluation metric will reveal not only a mathematical expression of how the overall experience varies depending on the other variables but it will give us an insight of the importance of each factor in the final objective function - the Overall User's Experience.

First we will study how each factor variation influences the overall experience value by exploring the curve type that models the evo-

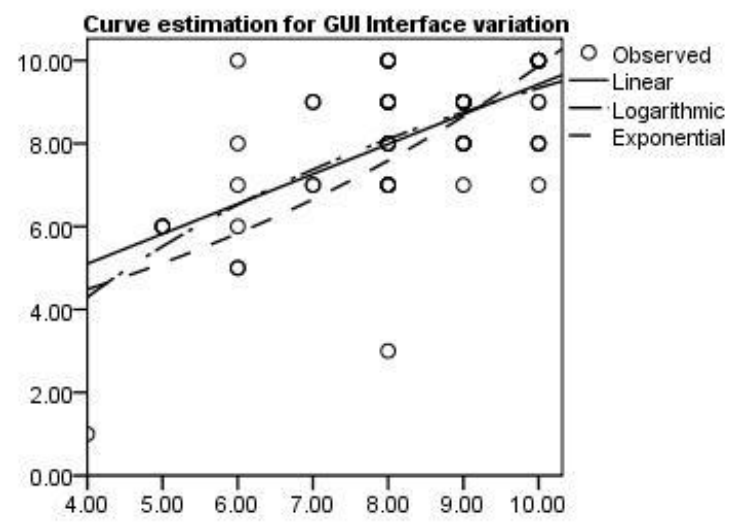

Fig. 7. Curve estimation for GUI interface level variation within Overall Experience metric lution of overall experience when each factor varies. We use Curve Estimation procedure to figure out which model is the best for expressing each variation in the objective metric. Figures 7, 8 and 9 depict curve estimations for each factor considering linear, logarithmic and exponential models.

Tables 7, 8 and 9 depict curve estimation summary for each factor variation within overall experience distribution. In all cases de $p$-value is very small and is less than 0.05 , concluding that all tested models can reliable predict the overall experience in relation with dependent variables. $F$ is the Mean Square Regression divided by Mean Square Residual and R Square represents the variance proportion in the dependent variable - Overall Experience which can be predicted from the independent variables - GUI, Content presentation and Interactivity [19]. For e.g. in Table 9 , if we consider the linear regression, a percent of $53.1 \%$ of the variance can be predicted from the Content Presentation variable. This measure is indicating the strength of association between dependent and independent variables.

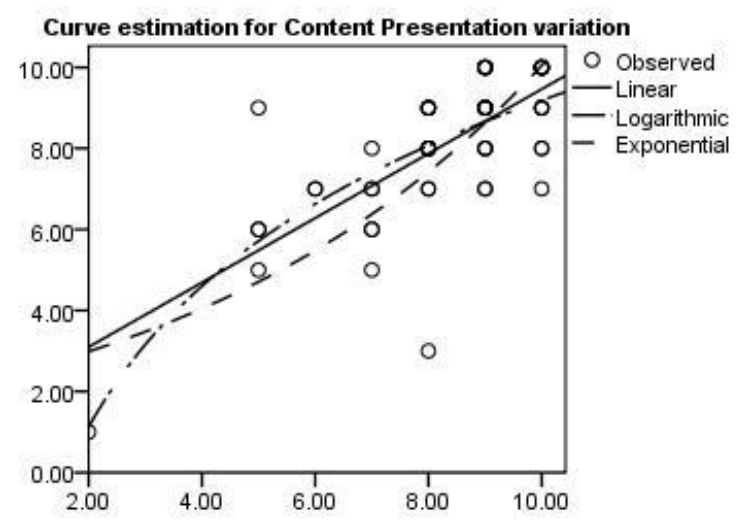

Fig. 8. Curve estimation for Content presentation level variation within Overall Experience metric 


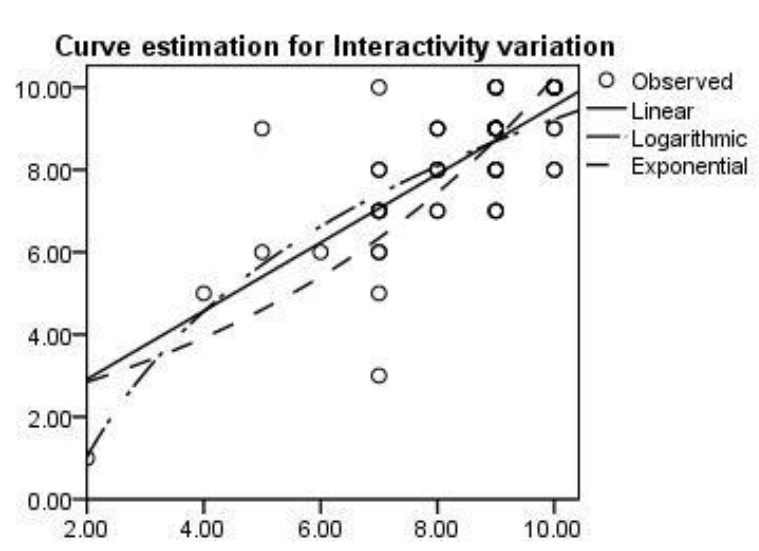

Fig. 9. Curve estimation for Interactivity level variation within Overall Experience metric

Table 8. Curve estimation - GUI variation

\begin{tabular}{|l|r|r|r|}
\hline \multirow{2}{*}{ Equation } & \multicolumn{4}{|c|}{$\begin{array}{c}\text { Curve estimation for GUI } \\
\text { Interface variation }\end{array}$} \\
\cline { 2 - 4 } & R Square & \multicolumn{1}{c|}{ F } & \multicolumn{1}{c|}{ p-value } \\
\hline Linear & .386 & 34.592 & .000 \\
\hline Logarithmic & .423 & 40.368 & .000 \\
\hline Exponential & .335 & 27.745 & .000 \\
\hline
\end{tabular}

Considering the p-values, we observe that there is no significant difference between the three tested models and the simpler model has priority. We choose linear regression model to build our metric for predicting the Overall Expression Index depending on Content presentation, Interactivity and graphical user interface evaluation.

We build the metric as a linear functional dependence. Let $\mathrm{E}$ be the Overall Experience, $g$ - graphical user interface, c - content presentation and $\mathrm{i}-$ interactivity. We need a model in form of (1) with $w_{1}, w_{2}, \mathrm{w}_{3}$ representing
Table 7. Curve estimation - Interactivity variation

\begin{tabular}{|l|r|r|r|}
\hline \multirow{2}{*}{ Equation } & \multicolumn{3}{|c|}{$\begin{array}{c}\text { Curve estimation for } \\
\text { Interactivity variation }\end{array}$} \\
\cline { 2 - 4 } & R Square & F & p-value \\
\hline Linear & .559 & 69.666 & .000 \\
\hline Logarithmic & .566 & 71.627 & .000 \\
\hline Exponential & .544 & 65.517 & .000 \\
\hline
\end{tabular}

Table 9. Curve estimation - Content variation

\begin{tabular}{|l|r|r|r|}
\hline \multirow{2}{*}{ Equation } & \multicolumn{3}{|c|}{$\begin{array}{c}\text { Curve estimation for Content } \\
\text { Presentation variation }\end{array}$} \\
\cline { 2 - 4 } & R Square & \multicolumn{1}{c|}{ F } & \multicolumn{1}{c|}{ p-value } \\
\hline Linear & .531 & 62.170 & .000 \\
\hline Logarithmic & .548 & 66.559 & .000 \\
\hline Exponential & .504 & 55.819 & .000 \\
\hline
\end{tabular}

the coefficients of importance for each dependent variable and $r$ the residual value.

$$
E(i, c, g)=w_{1} i+w_{2} c+w_{3} g+r
$$

Table 9 depicts the linear regression computation output of E. Column B shows the values of $w$ in the equation metric (1). The next columns provides the standard errors and Beta which represents the standardized coefficients of the regression model if all the variables where standardized. $\mathrm{T}$ and $\mathrm{p}$-value columns are used to test whether the coefficients are significantly different from 0 .

Table 10. Regression model for E metric

\begin{tabular}{|c|c|c|c|c|c|c|c|}
\hline \multirow[b]{2}{*}{ Model } & \multicolumn{2}{|c|}{$\begin{array}{l}\text { Unstandardized } \\
\text { Coefficients }\end{array}$} & \multirow{2}{*}{$\begin{array}{c}\text { Standardized } \\
\text { Coefficients }\end{array}$} & \multirow[b]{2}{*}{$\mathbf{t}$} & \multirow[b]{2}{*}{ p-value } & \multicolumn{2}{|c|}{ 95\% Confidence Interval for B } \\
\hline & B & Std. Error & & & & Lower Bound & Upper Bound \\
\hline (Constant) - r & .327 & .889 & & .368 & .714 & -1.456 & 2.111 \\
\hline GUI Interface $-w_{3}$ & .112 & .147 & .097 & .766 & .447 & -.182 & .407 \\
\hline Content Presentation $-\mathrm{w}_{2}$ & .359 & .161 & .329 & 2.236 & .030 & .037 & .681 \\
\hline Interactivity $-\mathrm{w}_{1}$ & .470 & .160 & .423 & 2.934 & .005 & .149 & .791 \\
\hline
\end{tabular}


The $p$-value is compared with $\alpha=0.05$ and for $\mathrm{p}$-values $<0.05$ the coefficients are significantly different from 0 .

In our case we observe that:

a. The constant $r$ has the $p$-value greater than 0.05 which means that it is not significantly different than 0 ;

b. The GUI interface coefficient- $w_{1}$ has the p-value greater than 0.05 which means that it is not significantly different from 0 ;

c. The Content presentation coefficient- $\mathrm{w}_{2}$ has the $\mathrm{p}$-value of $0.03<0.05, \mathrm{w}_{2}$ being significantly different from 0 ;

d. The interactivity coefficient $-w_{3}$ has the p-value of $0.005<0.05, w_{3}$ being significantly different from 0 ;

At a confidence interval of $95 \%$ the last column from Table 9 depicts the variation interval for each coefficient. The items that are significantly different from 0 do not contain 0 values in the coefficient variation intervals. Let $\mathrm{S}$ be the definition of an evaluation scale:

$$
\begin{aligned}
& \quad S=\left\{x \in N \mid \min \left(x_{0}, x_{1}, \ldots, x_{n}\right)\right. \\
& \leftarrow \text { minimum evaluation rank; } \\
& \max \left(x_{0}, x_{1}, \ldots, x_{n}\right) \\
& \leftarrow \operatorname{maximum} \text { evaluation rank; } x_{0}<x_{1} \\
& \left.<\cdots<x_{n}\right\}
\end{aligned}
$$

Our metric for expressing Overall Experience depending on GUI, Content and Interactivity evaluation would be expressed by equation (2):

$$
\begin{gathered}
E(i, c, g)=0.47 i+0.359 c+0.112 g+ \\
0.327 i, c, g, E \in S
\end{gathered}
$$

Having the Interactivity variable, Content variable and GUI variable evaluated on the same scale the comparability condition between independent variables is achieved. According to our model expressed in (2) we can conclude that the interactivity in our $\mathrm{M}$ Learning system prototype is the most important feature for achieving a higher positive overall user experience, followed by content presentation and graphical user interface design.

The fact that the graphical user interface component has less importance and is not significantly different from 0 in the model, can be explained by the high correlation between content presentation (correlation of 0.614 with GUI) respectively interactivity (correlation of 0.6 with GUI) and graphical user interface design. A highly interactive and effective content presentation will give higher evaluations for graphical user interface.

Model usage: Applied to our M-Learning prototype based on collected, the calculated metric for overall experience will be:

Average Interactivity Evaluation: 8.28

Average Content presentation Evaluation: 8.32

Average GUI Interface Evaluation: 8.19

$\mathrm{S}=\{(1,2, \ldots 10) \mid 1$ - very unattractive; $10-$ very attractive $\}$

$E \in[1,268 ; 9,737]$

$E=\mathbf{0 . 4 7} \times 8.28+\mathbf{0 . 3 5 9} \times 8.32+$

$\mathbf{0 . 1 1 2} \times 8.19+\mathbf{0 . 3 2 7}=8.122(3)$

Calculating de metric E using Average Interactivity, Content Presentation and GUI evaluations we obtained in (3) an average of 8.12 overall experience evaluation, value obtained in the collected data too (see Fig. 1).

\section{Conclusions}

M-Learning is an extension of E-learning and it represents a complementary tool for virtual learning process. Consequently, M-Learning can be a powerful instrument for continuous learning process, as mobile cloud based technologies and infrastructures expand. Choosing cloud computing as underlying technical layer for M-Learning can provide availability and elasticity of the resources delivered as a Learning as a Service model. M-Learning has the advantage of pervasive computing and mobility but is constrained to device resources and less informational content delivery. The limitation of the device hardware resources can be eliminated by deploying such applications in cloud, while the limited displays are requiring special treatment from the content presentation and interactivity point of 
view.

Virtual learning instruments have to implement pedagogical principles for training process and follow the technological constraints. Development of M-Learning tools needs special strategies which must follow the pedagogical principles and resolve the technical aspects too. We identified a convergence point between the software engineering knowledge field and educational programs design knowledge field in form of a prototyping strategy for designing and development of M-Learning tools.

A special attention requires the evaluation phase of the prototype from the user learning experience point of view. We proposed a regression based metric for evaluating the overall learning experience depending on interactivity, content presentation and graphical user interface. The model expresses the overall experience in a functional form using scale based evaluations of interactivity, content presentation and graphical user interface usability. Moreover, it provides an overview of the importance of each factor in the resulting metric: interactivity has the highest influence for the overall learning experience (47\%), followed by content presentation component $(35,9 \%)$ and graphical user interface $(11,2 \%)$. The rest of $5.9 \%$ represents other factors not included in the metric model. The model was constructed using statistical analysis of the data gathered from students who interacted with the proposed M-learning prototype and completed the evaluation survey of the prototype.

\section{Future Development}

Future prototype development will overcome some limitations observed during the evaluation process like scrolling problem which affects the user experience, reengineering a modular design of the framework, addressing some cross-browser and cross-device issues and integration with E-Learning systems (e.g. Moodle).

The model can be further validated and improved for future prototypes. Some special metrics for expressing cloud resource usage, needs and security might be useful to be developed.

\section{Acknowledgement}

This paper was supported by CNCS Young Researchers Teams Project - TE 316.

\section{References}

[1] P. Mell, T. Grance, (2013, April 28), "The NIST Definition of Cloud Computing - Recommendations of the National Institute of Standards and Technology" [Online]: http://csrc.nist.gov/publications/nistpubs/ 800-145/SP800-145.pdf

[2] A. Kundu, C. Barnejee, Priya Saha, "Introducing New Services in Cloud Computing Environment", International Journal of Digital Content Technology and its Application, Vol. 4, No. 5, 2010

[3] T. T. Goh, "Multiplatform E-Learning Systems and Technologies. Mobile Devices for Ubiquitous ICT-Based Education", New York: Information Science Reference, 2010, ISBN 978-1-60566704-1, pp. 42-43

[4] A. Butoi, N. Tomai, D. Mican, G. C. Silaghi, "Designing effective web-based MLearning systems", In Proceeding of the 12th International Conference on Informatics in Economy (ISSN: 2247 - 1480), Education, Research \& Business Technologies. Bucharest: ASE Publishing House, 2013.

[5] Gwo-Jen Hwang, Hsun-Fang Chang, "A formative assessment-based mobile learning approach to improving the learning attitudes and achievements of students", Computers \& Education 56 (2011) pp.1023-1031

[6] M. Wrszesien and M. Raya, "Learning in serious virtual worlds: Evaluation of learning effectiveness and appeal to students in the E-Junior project." Computers \& Education, pp. 178-187, August, 2010

[7] K. Mansureh and H. "2c" Atsusi, "Examining the pedagogical foundations of modern educational computer games", Journal of Computers \& Education, vol. 
51, no. 4, pp. 1729-1743, December, 2008.

[8] J. Robertson and C. Howells, "Computer game design: Opportunities for successful learning", Journal of Computers \& Education, vol. 50, no. 2, pp. 559-578, February, 2008.

[9] H. Chu, G. Hwang, C. Tsai and J. C.R. Tseng, "A two-tier test approach to developing location-aware mobile learning systems for natural science courses", Computers \& Education 55 (2010) 1618 1627

[10] A. Kukulska-Hulme, M. Sharples, M. Milrad, I. Arnedillo-S'anchez and G. Vavoula, "Innovation in Mobile Learning: A European Perspective", International Journal of Mobile and Blended Learning, 1(1), pp. 13-35, 2009.

[11] Mike Sharples, Dan Corlett and Oliver Westmancott, "The Design and Implementation of a Mobile Learning Resource"

[12] G. Didac, A. Jesper, M. Marcelo, S. Hakan, "Towards a Decentralized and Self-Adaptive System for M-Learning Applications", in Proc of the 2012 IEEE Seventh International Conference on Wireless, Mobile and Ubiquitous Technology in Education (WMUTE '12), Washington, DC, USA, 2012, pp. 162166.

[13] L. F. Motiwalla, "Mobile learning: A framework and evaluation", Journal of
Computers \& Education, vol. 49, no. 3, pp. 581-596, November 2007.

[14] S. S. Liaw, M. Hatala, H.M. Huang, "Investigating acceptance toward mobile learning to assist individual knowledge management: Based on activity theory approach", Journal of Computers \& Education, vol. 54, no. 2, pp. 446-454, February 2010

[15] R. Gafni, "Framework for Quality Metrics in Mobile-Wireless Information Systems", Interdisciplinary Journal of Information, Knowledge, and Management Volume 3, 2008

[16] National Oceanic and Atmospheric Administration - U.S. Department of Commerce, "Designing Education Projects. Second Edition", Internet: http://www.oesd.noaa.gov/ leadership/DEP_Manual_2ndEdt_Final.pdf, April 2009, [March, 28, 2013]

[17] B. Valdis, "Software Prototyping", Encyclopedia of Computer Science $4^{\text {th }}$ Edition, pp. 1636-1638, John Wiley and Sons Ltd., 2003;

[18] I. Ivan, C. Boja, Metode statistice în analiza software, ASE Publishing House, 2004

[19] Institute for Digital Resource and Education - UCLA (2013, April 30), "Annotated SPSS Output Regression Analysis" [Online], ats.ucla.edu/stat/spss/output/ reg_spss(long).htm

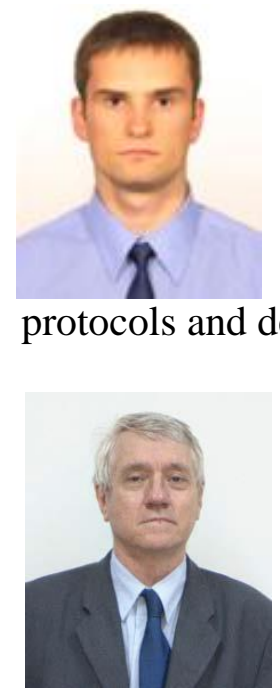

Alexandru BUTOI is a PhD student since October 2012, in the domain of Cybernetics and Statistics at Faculty of Economics and Business Administration, "Babeş-Bolyai" University of Cluj-Napoca. His main research interests are Web technologies and Mobile technology applied in business and lately, Cloud Computing, focusing on data security and privacy in Cloud Computing. He also worked on development of agent-based cloud resource negotiation protocols and developed a secure protocol for cloud storage environments.

Nicolae TOMAI is full Professor at Faculty of Economics and Business Administration, "Babeş-Bolyai" University of Cluj-Napoca. His main research areas are: Fundamentals of Computer Science, C\#, Computer Networks and Distributed Systems, E-business, Mobile systems. His work includes 19 books, 71 scientific papers published, 1 patent, innovation patent 5, active member in 18 research contracts. 


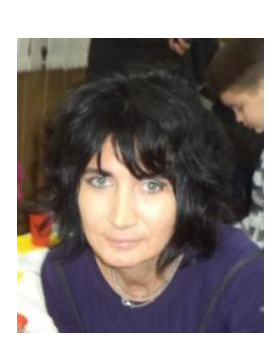

Loredana MOCEAN has graduated Babeş-Bolyai University of ClujNapoca, the Faculty of Computer Science, she holds a PhD diploma in Economics and she had gone through didactic position of assistant, lecturer and associate professor, since 2000 when she joined the staff of the Babeş- Bolyai University of Cluj-Napoca, Faculty of Economics and Business Administration. Also, she graduated Faculty of Economics and Business Administration. She is the author of more than 20 books and over 35 journal articles in the field of Databases, Data mining, Web Services, Web Ontology, ERP Systems and much more. She is member in more than 20 grants and research projects, national and international. 